K. C. NICOLAOU*, N. A. PETASIS, R. E. ZIPKIN, J. UENISHI (UNIVERSITY OF

PENNSYLVANIA, PHILADELPHIA, USA)

The Endiandric Acid Cascade. Electrocyclizations in Organic Synthesis. 1. Stepwise, Stereocontrolled Total Synthesis of Endiandric Acids A and B

J. Am. Chem. Soc. 1982, 104, 5555-5557.

K. C. NICOLAOU*, N. A. PETASIS, J. UENISHI, R. E. ZIPKIN

The Endiandric Acid Cascade. Electrocyclizations in Organic Synthesis. 2. Stepwise, Stereocontrolled Total Synthesis of

Endiandric Acids C-G

J. Am. Chem. Soc. 1982, 104, 5557-5558.

K. C. NICOLAOU*, R. E. ZIPKIN, N. A. PETASIS

The Endiandric Acid Cascade. Electrocyclizations in Organic Synthesis. 3. "Biomimetic" Approach to Endiandric Acids A-G.

Synthesis of Precursors

J. Am. Chem. Soc. 1982, 104, 5558-5560.

K. C. NICOLAOU*, N. A. PETASIS, R. E. ZIPKIN

The Endiandric Acid Cascade. Electrocyclizations in Organic Synthesis. 4. Biomimetic Approach to Endiandric Acids A-G. Total Synthesis and Thermal Studies

J. Am. Chem. Soc. 1982, 104, 5560-5562.

\title{
Total Synthesis of Endiandric Acids
}

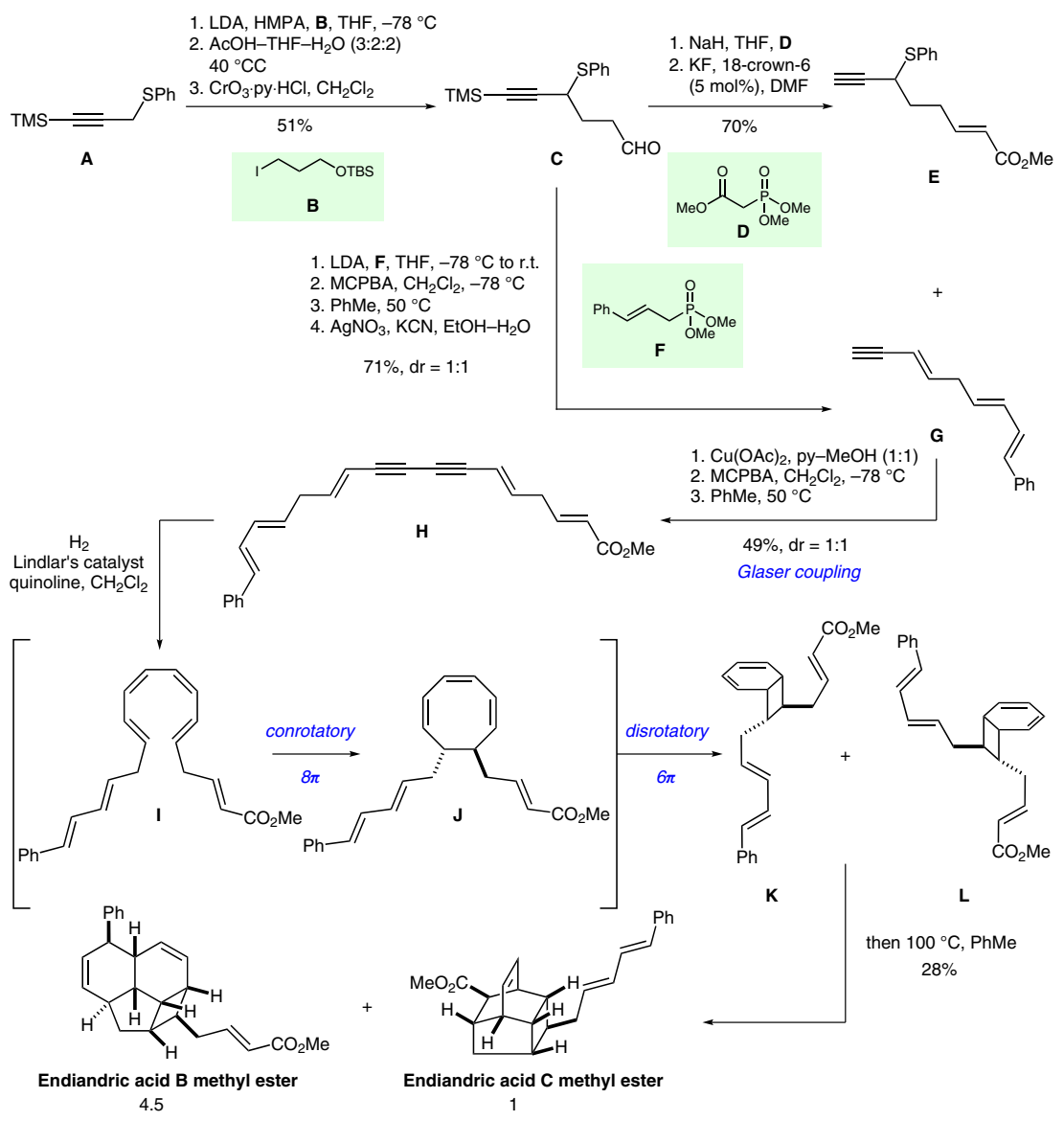

Significance: Nicolaou and co-workers describe the total synthesis of the endiandric acids. Their approach exploits a cascade of pericyclic reactions, which allow assembly of the carbon skeletons in one step. This pathway had been hypothesized to be the biosynthetic origin of these natural products.

SYNFACTS Contributors: Erick M. Carreira, Felix Pultar

Synfacts 2019, 15(06), 0589 Published online: 20.05.2019

DOI: 10.1055/s-0037-1611622; Reg-No.: C02819SF

\section{Category}

Synthesis of Natural

Products and

Potential Drugs

\section{Key words}

endiandric acids

electrocyclization

Glaser coupling

Diels-Alder reaction

biomimetic

synthesis
Comment: Aldehyde $\mathrm{C}$ was chosen as a common intermediate for the synthesis of alkynes $\mathbf{E}$ and $\mathbf{G}$. Glaser coupling, oxidation, and elimination results in the formation of dialkyne $\mathbf{H}$. Partial reduction to polyolefin I results in a series of electrocyclizations and cycloadditions giving rise to the target structures. 